\title{
Effects of animal-assisted activity on self- reported feelings of pain in hospitalized children and adolescents
}

\author{
Tatiane Ichitani ${ }^{*}$ (1) and Maria Claudia Cunha ${ }^{2}$
}

\begin{abstract}
Animal-assisted intervention (AAI) is an approach recently introduced into the hospital environment to improve the quality of hospitalization and provide important benefits for patients with chronic diseases and long-term hospitalizations. This work aims to verify the effects of animal-assisted activity (AAA) on the expression and quality of self-reported pain in hospitalized children and adolescents, while considering the subjects' subjectivity. The participants were 17 hospitalized children/adolescents of both genders, aged 7 years and older, who complained of pain. Two therapy dogs were selected for the intervention according to the criteria of international protocols. The participants were asked an open question ("How would you describe your pain?"). After the question, an AAA session, which lasted between 5 and 10 min, was held with random activities spontaneously chosen by the subject. The open question was asked again at the end of the session, without the presence of the dog. Positive effects were observed in this population with regard to a decrease in self-reported pain. These results suggest that there is a possible symbolic elaboration of pain by the subject, in which the dog might represent acceptance and affection at a moment of great emotional suffering.
\end{abstract}

Keywords: Animal-assisted intervention, Animal-assisted therapy, Pain, Hospitalization, Child, Adolescent

\section{Background}

Animal-assisted intervention (AAI) is an approach that is increasingly used in the context of health and education and encompasses animal-assisted therapy (AAT), a therapeutic intervention that is guided, structured, and planned with a defined purpose and monitored by healthcare professionals; animal-assisted education (AAE), an intervention with an objective that is guided, structured, planned, directly connected to education, and always monitored by a teacher and/ or educationalist; and animal-assisted activity (AAA), an informal yet planned intervention with educational, motivational, and recreational purposes (IAHAIO 2014).

AAI has been introduced in the hospital environment in the last decades with the goal of improving the quality of hospitalization. According to Barker et al. (2003), pediatric patients in contact with therapy animals have

\footnotetext{
* Correspondence: tatiane.ichitani@gmail.com

${ }^{1}$ Pontifícia Universidade Católica de São Paulo, Rua Assungui, 700 ap 191,

São Paulo, SP CEP 04131-001, Brazil

Full list of author information is available at the end of the article
}

reduced levels of stress and anxiety during painful procedures. In addition, the interaction draws the attention of children and parents towards the animals, improves the interpersonal relationship with the healthcare team, promotes self-care, fights depression, diminishes feelings of loneliness, and motivates physical activity while interacting with the animal. According to Morales (2005), AAI offers important benefits for patients with chronic diseases and long hospitalizations. The contact with the animal facilitates adaptation to the new and stressful environment, which helps to diminish anxiety, blood pressure, stress, and pain.

In a case report, a hospitalized child requested the company of their own dog, which shows that AAT provides therapeutic benefits to the patient's psychological health by providing moments of relaxation and humanized assistance for both the patient and their family (Bussotti et al. 2005).

In a study carried out in Italy, hospitalized children who were engaged in AAA increased their contact with their family members and medical team and stated that 
they felt motivated to communicate and strengthen their relationships, which suggests that the presence of the dog facilitated emotional expression (Caprilli and Messeri 2006).

Tsai et al. (2010) noticed a decrease in heart rate after AAT and suggested that the effects of AAT might last beyond the intervention. The authors also showed that the presence of a dog might be more effective than a visit from a person for alleviating physiological stress in hospitalized children and provides physiological and psychological benefits for family members and nurses.

Wu et al. (2002) observed that physical contact with a dog through AAI established harmony and produced positive feelings. At a pediatric oncology unit, bringing the child to the ground, putting the dog on the bed, or walking it along the hallway made patients and parents more satisfied. The presence of the animal made the hospital environment cozier, safer, and protected; promoted feelings of relaxation; and provided a normalizing experience for the children. Gagnon et al. (2014) observed that AAT eased the emotional suffering of children and parents (companions), facilitated adaptation to the therapeutic process, and promoted well-being during hospitalization.

Hospitalization is one of the most stressful events for a child and might cause high levels of anxiety, fear, and pain (Mahat and Scoloveno 2003). Pain can be defined as "an unpleasant sensory and emotional experience associated with actual or potential tissue damage, or described in terms of such damage" (IASP 2015). Pain encompasses sensitive, emotional, cognitive, and evaluative components (Frutuoso and Cruz 2004). Some factors might influence the expression of pain in children and adolescents, such as age, gender, cognitive level, previous experiences, cultural standards, family relationships, and repercussions on their routine (Puccini and Bresolin 2003).

Viana et al. (2006) confirmed that the evaluation of pain in children also depends on the nurse-patientfamily interaction. Building the nurse's awareness can increase the confirmation of pain and optimize treatment because there are subjective aspects of this profession that can influence the assessment of pain in intensive care patients. Silva et al. (2011) also observed that most professionals are extremely engaged in verifying pain in hospitalized patients, but are restricted pharmacologically, which makes it necessary to amplify this view as a whole and improve pain management.

In all cultures, pain is considered an unpleasant sensation. Its perception is acquired through self-observation and learning, and verbalization is one of the ways of communicating this sensation. Therefore, verbalization is helpful in conjunction with evaluation instruments because they make it possible to assess the psychological aspects of pain (Frutuoso and Cruz 2004).
According to Rossato and Angelo (1999), a child should be observed as someone who has a personal story and needs resources to evaluate pain in a more comprehensive way that accounts for the global experience of pain. The feelings and emotions used to express pain should not be discarded but should be taken into consideration as a part of the diagnosed pain and strategy for intervention.

AAI has been shown to significantly decrease the feelings of pain in addition to its effects on other important aspects of hospitalization, for example, promoting relaxation, pleasure, and acceptance (Sobo et al. 2006); reducing suffering and improving cognitive, social, and emotional functions (Vagnoli et al. 2015); and having a positive impact on the patient's family members and medical team (Marcus et al. 2012).

In this sense, this research intends to complement discussions on the topic by verifying the effects of AAA on the expression and quality of self-reported pain in hospitalized children and adolescents, while considering the subjects' subjectivity.

\section{Methods}

This research was carried out according to the regulating guidelines and norms of studies involving human subjects issued by the National Health Council, Resolution 196/96. Only subjects authorized by their parents or caretakers participated in the study after signing the Informed Consent Term.

This project was approved on 4 August 2014 by the PUC-SP Ethics Committee under CAAE number 31880314.4.0000.5482.

This research utilizes a qualitative intervention. According to Denzin and Lincoln (2006), qualitative research involves an interpretive approach to the world because the researchers study things in their natural settings and attempt to understand the meaning that people attach to the phenomena. According to Creswel (2007), qualitative research uses the natural environment as the direct source of data. The researcher is the main instrument, and the data they collect are predominantly descriptive. In addition, Creswel (2007) suggests that more concern is placed on the process than the product, which suggests that when studying a particular issue, the goal of the researcher is to determine how the issue is manifested in the activities, procedures, and interactions.

\section{Casuistry \\ Participants}

The participating subjects of this study were 17 hospitalized children/adolescents of both genders aged 7 years and older (attachment, Table 1). 
Table 1 Description of subjects

\begin{tabular}{|c|c|c|c|c|}
\hline Subject & Age & Gender & $I C D^{a}$ & Disease/symptom ${ }^{b}$ \\
\hline 1 & 11 years 1 month & $\mathrm{F}$ & R10 & Abdominal and pelvic pain \\
\hline 2 & 08 years 11 months & $\mathrm{F}$ & R10 & Abdominal and pelvic pain \\
\hline 3 & 10 years 08 months & $\mathrm{F}$ & R52 & Acute pain \\
\hline 4 & 12 years 04 months & M & R10 & Abdominal and pelvic pain \\
\hline 5 & 12 years 06 months & $\mathrm{F}$ & R51 & Headache \\
\hline 6 & 09 years 11 months & M & R10 & Abdominal and pelvic pain \\
\hline 7 & 17 years 04 months & $\mathrm{F}$ & R51 & Headache \\
\hline 8 & 13 years 04 months & M & D58 & Hereditary spherocytosis \\
\hline 9 & 10 years 04 months & $\mathrm{F}$ & J18 & Bronchopneumonia, unspecified \\
\hline 10 & 14 years 06 months & M & J03 & Streptococcal tonsillitis \\
\hline 11 & 17 years 04 months & M & L03 & Cellulitis of the finger and toe \\
\hline 12 & 07 years 06 months & M & R10 & Abdominal and pelvic pain \\
\hline 13 & 11 years 10 months & $\mathrm{F}$ & R10 & Abdominal and pelvic pain \\
\hline 14 & 13 years 00 months & $\mathrm{F}$ & R10 & Abdominal and pelvic pain \\
\hline 15 & 14 years 08 months & $\mathrm{F}$ & M30 & Polyarteritis nodosa \\
\hline 16 & 08 years 10 months & M & A97 & Dengue \\
\hline 17 & 11 years 01 month & M & R10 & Abdominal and pelvic pain \\
\hline
\end{tabular}

anternational Statistical Classification of Diseased and Related Health Problems-ICD

${ }^{\mathrm{b}}$ Based on an ICD medical chart

\section{Inclusion criteria}

The inclusion criteria included hospitalized children and adolescents in the admission center (private rooms) that have the capacity for verbal expression (which justifies the established age range of the patients); have pain complaints associated with any core pathology; are receptive to contact with the dogs; are in a physical condition that allows for interaction with the animal; have preserved cognition; are awake and conscious; and are able to answer the open question (even if unable to get out of bed).

\section{Exclusion criteria}

The exclusion criteria included hospitalized subjects in isolation who are severely allergic to dog hair and saliva, severely immunocompromised, and afraid of interacting with the dogs and who have difficulty communicating using verbal language.

\section{Location}

The study was conducted at the admission center of the pediatric care unit at the Hospital Infantil SabaráHIS (Sabará Children's Hospital) in São Paulo, SP. HIS has an Education and Research Center (PENSI Institute), whose purpose is to conduct research and promote education in the field of child and youth health and is where the first contact was made to obtain authorization for the study.

\section{Therapy animals}

Two therapy dogs participated in the study-Bruce, an 8-year-old Old English Sheepdog (large breed), and Sheep, a 6-year-old Shih-Tzu (small breed). Both dogs were neutered and underwent constant behavioral and health assessments for their own safety and the safety of the subjects. A total of two dogs were used in this study to allow the dogs to take turns with the patients, which ensured the animals' well-being during the data collection period.

\section{Procedure}

Health and behavior protocol used in this research

To ensure safety during the data collection, the following important health and behavior procedures, which were based on international protocols, were followed (Lefebvre et al. 2008):

a) Hand hygiene:

- The hands of the patient, companion, and team were cleaned before and after contact with the animal.

- The hands of the researcher were cleaned before and after each intervention with the patient.

b) Character of the animal:

- The animal's character and behavior are evaluated by examining the animal's reactions before strangers; reactions to loud sounds and/or a new stimulus; reactions to aggressive voices or 
threatening gestures; reactions to crowded places; reactions to strong, clumsy caressing; reactions to strong hugs; and reactions to other animals and the ability to follow commands given by the trainer.

- Visits were suspended if the animal behaved with fear or aggressiveness.

c) Health of the animal:

- The animals were vaccinated against rabies, V8 or V10, giardia, and kennel cough.

- The animal was not allowed to make the visit and stayed under observation for a week in cases of vomit or diarrhea, urinary or fecal incontinence, cough or sneeze of unknown causes, open wounds, ear infections, skin infections, or heat.

- The dogs were monitored and assessed by a veterinarian to control for fleas, ticks, and parasites and were withdrawn and treated for infestations.

- The dogs were routinely examined for parasites.

d) For the visits:

- The animal's fur was brushed before the visit.

- The animal was bathed within $24 \mathrm{~h}$ of the visit.

- The animal's nails were trimmed.

- The collars and leashes were kept clean and odorless.

- The animals were not allowed to have contact with immunocompromised or isolated patients.

\section{Introducing the therapy dogs to the hospital environment}

The therapy dogs were introduced to the environment at HIS to become familiarized with the general routine, noises, and smells. Two 30-min introductory visits were performed each week (one with each dog) during the month of September in the year 2014. One of the hospital's nurses was responsible for accompanying the dog during this procedure and to show them the admission center and the most appropriate places for the animals to be.

\section{Selection of the subjects}

Data were collected between October of 2014 and April of 2015.

The therapy shifts were conducted twice a week, one with each dog, on predetermined days. During the shift, the nurse who supervised the admission center passed by all the floors to assess the patients for complaints of pain. After the assessment, the patients who complained of pain were selected.

Once the hospital's protocol was effective regarding the use of procedures to ease the patient's suffering, it was difficult to obtain a high number of subjects.

\section{Data collection protocol}

Stage 1: The researcher entered the room without the dog. An open question was asked ("How would you describe your pain?"). A mobile recorder was turned on at this time and stayed on until the end of stage 3 . Stage 2: The AAA session, which lasted from 5 to $10 \mathrm{~min}$, was conducted with the dog. The dog's leash was removed during all interventions under the following conditions: the complexity of the patient was low, the environment was highly controlled with regard to noise and the circulation of people or equipment, and the dog had plenty of experience with AAI, which made it safe for all the parties involved. The activities were spontaneously chosen by the subject, and no suggestions were made by the researcher. The researcher kept her interference in the activities to a minimum and spoke only to answer questions, which were always about the dogs. Relevant comments from patients and caretakers were used in the results.

Stage 3: The open question was asked again at the end of the session, without the presence of the dog. At the end of the session, the recorder was turned off.

\section{Results interpretation criteria}

The interpretation of the material was based on a categorical analysis as described by Bardin (2010). This procedure involves the reorganization of dialogue according to theme categories that are established a posteriori based on the incidence and relevance of the themes with the aim to regroup the content of the dialogue around the objectives of the research. The content was analyzed using the following three steps. (1) Pre-analysis: the researcher chose the documents to be analyzed, formulated the hypotheses and objectives, and developed the indicators to substantiate the final interpretation. (2) Analytical description: the material was subjected to a thorough study that was guided by the hypotheses. Procedures such as coding, categorization, and classification are basic at this stage. (3) Referential interpretation: reflection and intuition based on the empirical materials to establish relationships and connections between the ideas. At this stage, the researcher deepens the analysis and reaches more specific results.

Relevant material recorded during the session was also interpreted but without categorization.

\section{Results}

The characteristics of the study population (17 subjects) are presented in Table 2 (attachment). There was a balanced distribution between the genders. The average age was 12.1 years $(\mathrm{sd}=2.8$ years, median $=11.8$ years, range $=7.5$ to 17.4 years) . 
Table 2 Number and percentage of hospitalized subjects, according to demographics and clinical characteristics

\begin{tabular}{|c|c|c|c|}
\hline Variable & Category & Number & Percent \\
\hline \multirow[t]{2}{*}{ Gender } & Feminine & 9 & 52.9 \\
\hline & Masculine & 8 & 47.1 \\
\hline \multirow[t]{2}{*}{ Type of disease } & Acute & 15 & 88.2 \\
\hline & Chronic & 2 & 11.8 \\
\hline \multirow[t]{2}{*}{ Painkiller } & No & 9 & 52.9 \\
\hline & Yes & 8 & 47.1 \\
\hline \multirow[t]{2}{*}{ Type of painkiller ${ }^{a}$} & Dipyrone or similar & 6 & 75 \\
\hline & Tramadol or similar & 2 & 25 \\
\hline \multirow[t]{2}{*}{ Receptivity $^{\mathrm{b}}$} & No & 1 & 5.9 \\
\hline & Yes & 16 & 94.1 \\
\hline \multirow[t]{2}{*}{ Willingness $^{\mathrm{b}}$} & No & 1 & 5.9 \\
\hline & Yes & 16 & 94.1 \\
\hline \multirow[t]{2}{*}{ Mobility } & No & 8 & 47.1 \\
\hline & Yes & 9 & 52.9 \\
\hline \multirow[t]{4}{*}{ Companions $^{c}$} & Mother & 13 & 76.5 \\
\hline & Father & 2 & 11.8 \\
\hline & Grandmother/grandfather & 1 & 5.9 \\
\hline & Uncle/aunt & 1 & 5.9 \\
\hline Total & & 17 & 100 \\
\hline
\end{tabular}

apercentage referring to the cases who took painkillers

${ }^{b}$ The subject, at first, refused the presence of the dog, but changed their mind and realized the whole protocol

'Only two subjects had more than one companion in the room

The most frequent painkiller was dipyrone (or similar), followed by tramadol (or similar). The average time between the ingestion of the medicine and the start of the AAA session was $129.6 \mathrm{~min}(\mathrm{sd}=78.4 \mathrm{~min}$, median $=$ $106.5 \mathrm{~min}$, minimum $=53 \mathrm{~min}$, and maximum $=266 \mathrm{~min}$ ).

The results showed that $58.8 \%$ (10 patients) of the activities were performed with the dog Bruce. Because it is a convenience sample, the number of activities with each of the dogs depended on the number of patients during each shift. It is worth highlighting that all the subjects performed at least two activities with the dogs during each session. The most common activities were "petting" and "talking," followed by "taking photos," "offering treats," "playing," and "asking for obedience command."

Table 3 shows the significant content expressed in the answers to the open question (before and after the AAA).

The responses to the open question were grouped into the following four categories, which were defined a posteriori from the main responses of the sample:

1. Feelings (impression of the pain)

2. Part of the body (location of the pain)

3. Intensity of the pain

4. Other comments
Table 4 (attached) shows the answers that were given before the intervention with the dog.

Table 5 (attached) shows the answers that were given after the AAA.

Some important data were observed during the collection of data; however, it was not part of the protocol.

On all the shifts, hospital professionals from several areas had some type of contact with the dogs. The dogs were identified at the entrance of the hospital and were recognized by the guards, receptionists, nurses, cleaning staff, and others. Parents and companions of many of the patients (not only the participating subjects) also interacted with the dogs.

At the beginning of the intervention, most of the subjects in this study were lying in bed (some in the dark), with the windows of their rooms closed. As soon as the dog came in, there was a change in these aspects; the patients got out of bed or asked that the back of the bed was lifted, the windows were opened, the lights were turned on, and the patients asked that their hair was brushed and their clothes were changed.

Some of the subjects, although not referring to a decrease in pain after the AAA, showed improvement in mood and motivation as reported by their companions. One of the patient's companions stated that the child was not motivated to talk that day, but that after the arrival of the dog, the patient talked and smiled. Another companion reported that the patient only wanted to lie down due to the pain, but that in the presence of the dog, they sat up.

We highlight that the only subject that reported an increase in pain after the AAA credited it to the uncomfortable position (seating) that they were in during the intervention, which might have caused by their complaint (abdominal pain); however, they did not make any reference to this discomfort during the procedure. In contrast, this patient interacted with the dog, pet him, smiled, and told stories about their own dog.

One highlight of the results concerned a subject who answered negatively to the assessment of receptiveness and willingness to interact with the dog and, when consulted about participating, was crying and dispirited because of their disease, treatment, and having to answer the open question. However, after they were asked the question, they started asking the researcher questions about the animal, such as "Is he big or small?"; "Does he lick?"; and "Is he going to jump on me?" Subsequently, this patient changed their mind, stopped crying, requested the presence of the dog, and happily interacted with him.

Some of the nurses, upon informal request, appointed patients to the AAA who had no complaints of pain but were in a poor emotional state. We considered that these subjects - a girl with a panic syndrome, a boy 
Table 3 Significant content expressed in the answers to the open question (before and after the AAA)

\begin{tabular}{|c|c|c|}
\hline Subjects & Pain before & Pain after \\
\hline 1 & $\begin{array}{c}\text { Seems like taking a knife and keep } \\
\text { pressing it. Sometimes, it feels like a } \\
\text { needle. }\end{array}$ & I even forgot about the pain. \\
\hline 2 & I can't explain. It's weak. & It's better than it was before. \\
\hline 3 & $\begin{array}{l}\text { In the bone, but I can move. It hurts a } \\
\text { lot. }\end{array}$ & None. \\
\hline 4 & $\begin{array}{l}\text { Seems it's cutting, sometimes. On } \\
\text { the right side (points to the } \\
\text { abdomen). }\end{array}$ & It's the same thing. \\
\hline 5 & $\begin{array}{l}\text { It just hurts. The leg gets numb. } \\
\text { Dizziness. }\end{array}$ & $\begin{array}{l}\text { Sometimes it hurts a lot. Sometimes } \\
\text { it hurts a little. It's still numb (points to } \\
\text { the leg). }\end{array}$ \\
\hline 6 & $\begin{array}{l}\text { It burns here (points to the stomach) } \\
\text { and makes a wave on the belly. }\end{array}$ & $\begin{array}{l}\text { It burns here (points to the stomach) } \\
\text { when I eat. It hurts on the belly. }\end{array}$ \\
\hline 7 & The pain doesn't go away. It persists. & It's gone, I got distracted. \\
\hline 8 & Back pain. Just pain. & It doesn't hurt anymore. It's really gone. \\
\hline 9 & $\begin{array}{l}\text { It hurts on the surgery (shows the side } \\
\text { of the abdomen). The ear hurts too. }\end{array}$ & It still hurts, but I'm better. \\
\hline 10 & $\begin{array}{l}\text { Sore throat. It scratches when I } \\
\text { swallow. I can't swallow saliva. }\end{array}$ & Same thing. \\
\hline 11 & $\begin{array}{l}\text { A twinge. It pants. The place where } \\
\text { the drain was bothers me when I } \\
\text { walk. }\end{array}$ & Playing was enough to make it better. \\
\hline 12 & $\begin{array}{c}\begin{array}{l}\text { Regular pain. It hurt a little before, like } \\
\text { diarrhea. }\end{array} \\
\end{array}$ & Now I feel zero. \\
\hline 13 & $\begin{array}{l}\text { It comes and goes. It seems like a } \\
\text { punch in the stomach. }\end{array}$ & $\begin{array}{c}\text { It has increased. I think it's because I } \\
\text { was sitting. The position was } \\
\text { uncomfortable. }\end{array}$ \\
\hline 14 & $\begin{array}{l}\text { As if it was burning or pressing } \\
\text { (points to the belly). }\end{array}$ & The same. It feels like pressure. \\
\hline 15 & A lot of pain all over the body. & $\begin{array}{l}\text { It's the same. Everything gets hard, } \\
\text { the body stops obeying. I get limited } \\
\text { movement. }\end{array}$ \\
\hline 16 & $\begin{array}{c}\text { I can't explain. The head and the belly } \\
\text { hurt. A lot. }\end{array}$ & $\begin{array}{l}\text { On the belly and on the head. I don't } \\
\text { know anything else. }\end{array}$ \\
\hline 17 & Strong. & $\begin{array}{l}\text { A twinge on this side (points to the } \\
\text { right side of the abdomen). }\end{array}$ \\
\hline & Same feeling of pain after & \\
\hline & Less feeling of pain after & \\
\hline & More feeling of pain after & \\
\hline
\end{tabular}

whose mother passed away while he was hospitalized, a boy with leukemia who was "sad," and a baby who had been crying for over $30 \mathrm{~min}$-could benefit from the presence of the dog.

\section{Discussion}

In this study, we verified that some of the subjects in the study population showed positive reductions in selfreported feelings of pain following the AAA.
Sobo et al. (2006) indicated that AAA reduces physical and emotional pain in children when used in conjunction with pharmacological treatment. Braun et al. (2009) concluded that AAI could be used as supplemental therapy to reduce pain and stress in children during hospitalization. Marcus et al. (2012) showed that, at a clinic specializing in the treatment of pain, adult patients with chronic pain had a significant reduction in pain and emotional suffering after a quick AAI session with a dog in the waiting room. 
Table 4 Answers before the intervention, by categories (in parenthesis, the number corresponded to the subject)

\begin{tabular}{|c|c|c|c|c|}
\hline Answers before AAA & Feeling & Parts of the body & Intensity & Other comments \\
\hline \multirow[t]{6}{*}{ Feeling } & \multirow{6}{*}{$\begin{array}{l}\text { Seems like taking a knife } \\
\text { and keep pressing it. } \\
\text { Sometimes, it feels like } \\
\text { a needle. (1) }\end{array}$} & $\begin{array}{l}\text { Seems it's cutting, sometimes. } \\
\text { On the right side (points to } \\
\text { the abdomen). (4) }\end{array}$ & \multirow[t]{6}{*}{$\begin{array}{l}\text { Regular pain. It hurt a little } \\
\text { before, like diarrhea. (12) }\end{array}$} & \multirow[t]{6}{*}{$\begin{array}{l}\text { It just hurts. The leg gets } \\
\text { numb. Dizziness. (5) }\end{array}$} \\
\hline & & $\begin{array}{l}\text { It burns here (points to the } \\
\text { stomach) and makes a wave } \\
\text { on the belly. (6) }\end{array}$ & & \\
\hline & & $\begin{array}{l}\text { Sore throat. It scratches when } \\
\text { I swallow. I can't swallow } \\
\text { saliva. (10) }\end{array}$ & & \\
\hline & & $\begin{array}{l}\text { A twinge. It pants. The place } \\
\text { where the drain was bothers } \\
\text { me when I walk. (11) }\end{array}$ & & \\
\hline & & $\begin{array}{l}\text { It comes and goes. It seems } \\
\text { like a punch in the stomach. (13) }\end{array}$ & & \\
\hline & & $\begin{array}{l}\text { As if it was burning or pressing } \\
\text { (points to the belly). (14) }\end{array}$ & & \\
\hline \multirow[t]{3}{*}{ Parts of the body } & & \multirow{3}{*}{$\begin{array}{l}\text { It hurts on the surgery (shows } \\
\text { the side of the abdomen). The } \\
\text { ear hurts too. (9) }\end{array}$} & $\begin{array}{l}\text { I can't explain. The head and } \\
\text { the belly hurt. A lot. (16) }\end{array}$ & \multirow[t]{3}{*}{ Back pain. Just pain. (8) } \\
\hline & & & $\begin{array}{l}\text { A lot of pain all over the } \\
\text { body. (15) }\end{array}$ & \\
\hline & & & $\begin{array}{l}\text { In the bone, but I can move. } \\
\text { It hurts a lot. (3) }\end{array}$ & \\
\hline \multirow[t]{2}{*}{ Intensity } & & & Strong. (17) & I can't explain. It's weak. (2) \\
\hline & & & & $\begin{array}{l}\text { The pain doesn't go away. } \\
\text { It persists. (7) }\end{array}$ \\
\hline Other comments & & & & \\
\hline
\end{tabular}

Table 5 Answers after the intervention, by categories (in parenthesis, the number corresponded to the subject)

\begin{tabular}{|c|c|c|c|c|}
\hline Answers after AAA & Feeling & Parts of the body & Intensity & Other comments \\
\hline \multirow[t]{2}{*}{ Feeling } & & $\begin{array}{l}\text { It burns here (points to the stomach) } \\
\text { when I eat. It hurts on the belly. (6) }\end{array}$ & $\begin{array}{l}\text { Sometimes it hurts a lot. } \\
\text { Sometimes it hurts a little. } \\
\text { It's still numb (points to } \\
\text { the leg). (5) }\end{array}$ & The same. It feels like pressure. (14) \\
\hline & & $\begin{array}{l}\text { A twinge on this side (points to the } \\
\text { right side of the abdomen). (17) }\end{array}$ & $\begin{array}{l}\text { It has increased. I think it's } \\
\text { because I was sitting. } \\
\text { The position was } \\
\text { uncomfortable. (13) }\end{array}$ & $\begin{array}{l}\text { It's the same. Everything gets hard, } \\
\text { the body stops obeying. I get } \\
\text { limited movement. (15) }\end{array}$ \\
\hline Parts of the body & & & & $\begin{array}{l}\text { On the belly and on the head. I } \\
\text { don't know anything else. (16) }\end{array}$ \\
\hline Intensity & & & Now I feel zero. (12) & \\
\hline \multirow[t]{9}{*}{ Other comments } & & & & I even forgot about the pain. (1) \\
\hline & & & & It's better than it was before. (2) \\
\hline & & & & None. (3) \\
\hline & & & & It's the same thing. (4) \\
\hline & & & & It's gone, I got distracted. (7) \\
\hline & & & & It doesn't hurt anymore. It's really gone. (8) \\
\hline & & & & It still hurts, but I'm better. (9) \\
\hline & & & & Same thing. (10) \\
\hline & & & & Playing was enough to make it better. (11) \\
\hline
\end{tabular}


Improvement following AAA was also observed in the physiological indicators of pain, such as a reduction in heart rate, blood pressure, body temperature, respiration, and pupillary constriction, which suggests relaxation (Cole and Gawlinski 2000) and a decrease in pain.

In addition, the research suggests that AAI can lead to distraction from/redirecting of a problem, which is a possible explanation for the decrease in pain. One study indicated that the dog diverts the attention of the child who is under emotional distress (Johnson et al. 2008).

In Table 4, we can observe comments such as "I forgot about the pain" and "I got distracted." Moreover, some subjects made a point to show photos of their own dog, whereas others suggested that their own dog could visit them at the hospital. According to Tsai et al. (2010), AAA is often more effective at easing symptoms of stress and anxiety in hospitalized children than a visit from a person.

It is worth highlighting that both the patient's companions and the hospital professionals also sought to interact with the dogs, which fostered an atmosphere of ease and relaxation. These data corroborate the findings of Marcus et al. (2012), who stated that AAI benefits health professionals, which are regularly exposed to stressful work conditions. Another study showed that there was a significant decrease in salivary cortisol (stress hormone) in hospital professionals after $5 \mathrm{~min}$ of contact with a dog (Barker et al. 2005).

The subjects who changed their attitude prior to interacting with the dog (asking someone to open the window, brush their hair, or change their clothes) corroborate the findings of Souter and Miller (2007), who showed that AAI significantly reduces depression symptoms, and Banks and Banks (2005), who demonstrated a decrease in feelings of loneliness (particularly in individual visits). From this perspective, it is also possible to associate the psychological benefits with the decrease in the feelings of pain.

As for the subject who reported increased pain after the AAA and the one who did not want to see the dog at first, both fit the findings of Kaminski et al. (2002), who verified the positive effects of AAA on the mood of hospitalized children, which might justify the motivation of these subjects to participate in the AAA despite their discomfort and emotional suffering.

In this study, two therapy dogs of different sizes were used. It is worth highlighting that in situations where the subject was unable to leave the bed, Sheep (the small dog) was put on their lap or a chair beside their bed. In this same context, Bruce (the large dog) rested his head on the bed so he could be petted. Both forms facilitated and motivated affectionate and close interactions.

However, the large dog triggered the following important positive identifications: the children admired his strength and size, commenting: "He probably never gets sick, right?"; “One day, I want to take him for a walk!"; and "Does he eat a lot?" In many cases, identification ${ }^{1}$ and projection ${ }^{2}$ were noticed, which suggests symbolic elaboration by the subject before the experience. According to Levinson (1969), the child sees the possibility of incorporating the animal's strength through identification because the animal also possesses feelings such as sadness, anger, and loneliness.

One of the subjects got out of bed and hid objects for the small dog to find, pretending they were hidden treasures. According to Winnicott (1975), playing has an important role in the elaboration of the subject's internal issues and is a possible way to control anxiety, ideas, and impulses, which suggests that the interaction with the animal can create a potential space that makes it possible to have a creative experience of elaboration and reorganization between the external and internal world.

Regarding the verbalization of feelings of pain, Table 3 shows the answers given before the intervention with the dog. Verbalization, in most cases, revolves around feeling + parts of the body. The subjects described their pain as a "scratchy throat," "pressure on the belly," "like a punch in the stomach," or something more defined and concrete. Table 4 shows the answers given after the AAA. Verbalization centers on the "other comments" category, which indicates vague feelings of pain after contact with the dog. These results suggest that the pain had "diluted" and was not the main focus anymore, and the comments ranged from "It doesn't hurt anymore," "It's gone," and "No pain." In these cases, the subject's verbalization before and after the AAA lead to symbolic elaboration of their feeling and also corroborate the findings of Sobo et al. (2006), whose research subjects, in an interview, identified the dog as something that created a distraction and entertainment.

In the cases where pain was still present after the AAA, the answers were "It still hurts, but I'm better," "It's better than before," or "Playing was enough to make it better," which suggests that the subjects felt better than before the intervention, as suggested by Cole and Gawlinski (2000). Although the physical pain remains, the dog is able to reduce, neutralize, and potentiate the negative feelings and sensations so that the patient becomes more tolerant to pain and replaces the absence of affection and feelings of neglect and abandonment (Moraes and Melo 2014).

Because hospitalization is one of the most stressful events for a child (Mahat and Scoloveno 2003), we were able to generally observe that based on the accounts of the companions and the observations of the researchers, the AAA resulted in positive psychological effects for the subjects, such as improved mood/smiles (Kaminski et al. 2002), sociability/conversations (Wu et al. 2002), motivation/getting out of the bed (Sobo et al. 2006), and depressed feelings/stopped crying (Kamioka et al. 2014). 
Both the subjects and companions made contact with the animal during the intervention, which suggests that the dog promotes increased expression of emotions and provides support during difficult periods such as hospitalization. The parents/companions must also address feelings of powerlessness, changes in their routine, and giving up the comfort of their homes. The dog can also help them face the disease and treatment (Bussotti et al. 2005).

Patients who were informally appointed by the nurses and did not have complaints of pain but were fragile also benefited from the contact with the dog. Through the sessions, we verified that nurses are professionals who are very sensitive to their patient's condition and seek to improve their well-being and humanize their care (Kawakami and Nakano 2002).

The concept that AAI can be an important tool in the hospital environment is justified by the humanized approach to healthcare, in which dogs, in particular, have offered significant contributions based on numerous accounts of experiences in the field. However, the topic lacks solid scientific evidence, which should be gathered through intensive theoretical and methodological research.

\section{Limitations of this research}

The first limitation is the relationship between the nurse and patient. The nurse identified the patients with pain; therefore, we cannot rule out the question of empathy in this relationship, which is completely subjective.

The second limitation is the difference in the route of application (oral or intravenous) and type of analgesics (dipyrone, paracetamol, tramal, or morphine), which could change the effects of the medication on pain and interfere with the results.

According to the results and the finding by Odendaal (2000), the amount of time the patients interacted with the dog (maximum $10 \mathrm{~min}$ ) did not correspond to the peak release of hormones such as oxytocin (15 to $20 \mathrm{~min}$ ), which are directly linked to feeling less pain. However, there was a decrease in the sensation of pain sensation. Is this a result of the possible symbolic elaboration during the interaction? Are distraction and changing focus from the pain sufficient to reduce pain in some patients? How long do the effects of the interaction persist after the session ends?

The type of interaction with the dog can also be considered a limitation of the study because we did not specify the activity to be performed. The type of interaction can also be influenced by whether the patient has a pet at home, which was not considered during this study.

The sample size can also be considered a limitation. Future research should be conducted with a larger sample.

\section{Conclusions}

Positive effects of AAA have been observed regarding decreased self-reported feelings of pain in children. It was suggested that AAA may cause symbolic elaboration of the subject's pain and that the dog can represent acceptance and affection at a moment of great emotional suffering. Both physiological and psychological issues should be taken into consideration in an integrated way.

Another key finding is that the introduction of the animals to the hospital environment generally resulted in clear benefits. This work begins the discussion of animal-assisted intervention, which is extremely important because it is a topic that increases each day in our country and is already used by many health and educational professionals.

\section{Endnotes}

${ }^{1}$ The identification mechanism enables the subject to "assimilate an aspect, a property, an attribute of the other, and is totally or partially transformed according to the other's model" (Laplanche and Pontalis 2001, p. 226).

${ }^{2}$ Projection is a defense mechanism that makes it possible to locate and deposit in the other feelings and desires that the subject refuses in him- or herself (Laplanche and Pontalis 2001).

\section{Authors' contributions}

TI conceived the study, participated in its design, and draft and authored the manuscript. MCC participated in the study design and interpretation of the data and drafted the manuscript revisions. Both authors read and approved the final manuscript.

\section{Competing interests}

The authors declare that they have no competing interests.

\section{Author details}

${ }^{1}$ Pontifícia Universidade Católica de São Paulo, Rua Assungui, 700 ap 191, São Paulo, SP CEP 04131-001, Brazil. ²Pontifícia Universidade Católica de São Paulo (PUC-SP), Rua Ministro Godoi, 969 - 40 andar - sala 4E-13 - Perdizes, São Paulo, SP CEP 05015-901, Brazil.

Received: 12 July 2016 Accepted: 26 September 2016

Published online: 06 October 2016

\section{References}

Banks, M. R., \& Banks, W. A. (2005). The effects of group and individual animal-assisted therapy on loneliness in residents of long-term care facilities. Anthrozoös, 18(4), 396-408.

Bardin, L. (2010). Análise de conteúdo, Lisboa (70th ed., p. 281).

Barker, S. B., Knisely, J. S., McCain, N. L., \& Best, A. M. (2005). Measuring stress and immune response in healthcare professionals following interaction with a therapy dog: a pilot study. Psychological Reports Journal, 96(3), 713-29. doi:10.2466/pro.96.3.713-729.

Barker, S. B., Pandurangi, A. K., \& Best, A. M. (2003). Effects of animal-assisted therapy on patient's anxiety, fear and depression before ECT. The Journal of $E C T, 19(1), 38-44$.

Braun, C., Stangler, T., Narveson, J., \& Pettingell, S. (2009). Animal-assisted therapy as a pain relief intervention for children. Complementary Therapies in Clinical Practice, 15(2), 105-109. http://dx.doi.org/10.1016/j.ctcp.2009.02.008.

Bussotti, E. A., Leão, E. R., Chimentão, D. M. N., \& Silva, C. P. R. (2005). Assistência Individualizada: "Posso trazer meu cachorro?" Revista da Escola de Enfermagem da USP, 39(2), 195-201. http://dx.doi.org/10.1590/S0080-62342005000200010. 
Caprilli, S., \& Messeri, A. (2006). Animal-assisted activity at A. Meyer Children Hospital: a pilot study. eCAM, 3(3), 379-83. http://dx.doi.org/10.1093/ecam/nel029.

Cole, K., \& Gawlinski, A. (2000). Animal-assisted therapy: the human-animal bond. American Association of Critical-care Nurses Clinical Issues, 11(1), 139-149. doi:10.1097/00044067-200002000-00015.

Creswel, J. W. (2007). Projeto de pesquisa: método qualitativo, quantitativo e misto (2nd ed.). Porto Alegre: Artmed.

Denzin, N. K. \& Lincoln, Y. S. (2006). Introdução: a disciplina e a prática da pesquisa qualitativa. In N. K. Denzin \& Y. S. Lincoln (Eds.), O planejamento da pesquisa qualitativa: teorias e abordagens (2nd ed., pp. 15-41). Porto Alegre: Artmed.

Frutuoso, J. T., \& Cruz, R. M. (2004). Relato verbal na avaliação psicológica da dor. Avaliação Psicológica, 3(2), 107-114.

IAHAIO. (2014). IAHAIO white paper. www.iahaio.org/new/fileuploads/9313IAHAIO \%20WHITE\%20PAPER\%20TASK\%20FORCE\%20-\%20FINAL\%20REPORT.pdf. Retrieved 3 October 2016

IASP. http://www.iasp-pain.org/Taxonomy\#Pain. Retrieved 3 October 2016.

Johnson, R. A., Meadows, R. L., Haubner, J. S., \& Sevedge, K. (2008). Animal-assisted activity among patients with cancer: effects on mood, fatigue, self-perceived health, and sense of coherence. Oncology Nursing Forum, 35(2), 225-232.

Kaminski, M., Pellino, T., \& Wish, J. (2002). Play and pets: the physical and emotional impact of child life and pet therapy on hospitalized children. Children's Health Care, 31(4), 321-335. http://dx.doi.org/10.1207/S15326888CHC3104_5.

Kamioka, H., Okada, S., Tsutani, K, Park, H., Okuizumi, H., Handa, S., Oshio, T., Park, S., Kitayuguchi, J., Abe, T., Honda, T., \& Mutoh, Y. (2014). Effectiveness of animal-assisted therapy: a systematic review of randomized controlled trials. Complementary Therapies in Medicine, 22(2), 371-390. http://dx.doi.org/10.1016/j.ctim.2013.12.016.

Kawakami, C. H., \& Nakano, C. K. (2002). Relato de experiência: terapia assistida por animais (TAA)_mais um recurso na comunicação entre paciente e enfermeiro. Simpósio Brasileiro de Comunicação em Enfermagem, 8, São Paulo.

Laplanche, J., \& Pontalis, J. B. (2001). Vocabulário de Psicanálise (4ath ed.). São Paulo: Martins Fontes.

Lefebvre, S. L., Golab, G. C., Christensen, E., Castrodale, L., Aureden, K. Bialachowski, A., Gumley, N., Robinson, J., Peregrine, A., Benoit, M., Card, M. L., Horne, L. V., \& Weese, J. S. (2008). Guidelines for animal-assisted interventions in health care facilities. American Journal of Infection Control, 36(2), 78-85. http://dx.doi.org/10.1016/j.ajic.2007.09.005.

Levinson, B. M. (1969). Pet-oriented child psychotherapy. Springfield: Charles C. Thomas.

Mahat, G., \& Scoloveno, M. (2003). Comparison of fears and coping strategies reported by Nepalese school-age children and their parents. Journal of Pediatrics Nursing, 18(5), 305-313. http://dx.doi.org/10.1016/S0882-5963(03)00102-7.

Marcus, D. A., Bernstein, C. D., Constantin, J. M., Kunfel, F. A., Breuer, P., \& Hanlon, R. B. (2012). Animal-assisted therapy at an outpatient pain management clinic. Pain Medicine, 13(1), 45-57. http://dx.doi.org/10.1111/j.1526-4637.2011.01294.x.

Moraes, H. S., \& Melo, M. M. (2014). A relação do sujeito contemporâneo e o animal doméstico: uma análise a partir do filme Marley e Eu (MOSTRA DE INICIAÇÃO CIENTÍFICA DO CURSO DE PSICOLOGIA DA FSG. Anais da mostra de iniciação científica do curso de psicologia da FSG, pp. 127-151).

Morales, L. J. (2005). Visita terapêutica de mascotas em hospitales. Revista chilena de infectología, 22(3), 257-263. http://dx.doi.org/10.4067/S071610182005000300007 .

Odendaal, J. S. (2000). Animal-assisted therapy—magic or medicine? Journal of Psychosomatic Research, 49(4), 275-280. http://dx.doi.org/10.1016/S00223999(00)00183-5.

Puccini, R. F., \& Bresolin, A. M. B. (2003). Dores recorrentes na infância e na adolescência. Jornal de Pediatria (Rio J), 79(1), S65-S76. doi:0021-7557/03/79-Supl.1/S65.

Rossato, L. M., \& Angelo, M. (1999). Utilizando instrumentos para avaliação da percepção de dor em pré-escolares face a procedimento doloroso. Revista da Escola de Enfermagem da USP, 33(3), 236-49. http://dx.doi.org/10.1590/ S0080-62341999000300005.

Silva, M. S., Pinto, M. A., Gomes, L. M. X., \& Barbosa, T. L. A. (2011). Dor na criança internada: a percepção da equipe de enfermagem. Rev Dor, 12(4), 314-320.

Sobo, E. J., Eng, B., \& Kassity-Krich, N. (2006). Canine visitation (pet) therapy: pilot data on decreases in child pain perception. Journal of Holistic Nursing, 24(1), 51-7. doi:10.1177/0898010105280112.

Souter, M. A., \& Miller, M. D. (2007). Do animal-assisted activities effectively treat depression? A meta-analysis. Anthrozoös, 20(2), 167-180.

Tsai, C. C., Friedmann, E., \& Thomas, S. A. (2010). The effect of animal-assisted therapy on stress responses in hospitalized children. Anthrozoös, 23(3), 245-258.

Vagnoli, L., Caprilli, S., Vernucci, C., Zagni, S., Mugnai, F., \& Messeri, A. (2015). Can presence of a dog reduce pain and distress in children during venipuncture? Pain Management Nursing, 16(2), 89-95. http://dx.doi.org/10.1016/j.pmn.2014.04.004.
Viana, D. L., Dupas, G., \& Pedreira, M. L. G. (2006). A avaliação da dor da criança pelas enfermeiras na Unidade de Terapia Intensiva. Pediatria, 28(4), 251-261. Winnicott, D. W. (1975). O brincar e a realidade. Rio de Janeiro: Imago.

Wu, A. S., Niedra, R., Pendergast, L., \& McCrindle, B. W. (2002). Acceptability and impact of pet visitation on a pediatric cardiology inpatient unit. Journal of Pediatric Nursing, 17(5), 354-362.

\section{Submit your manuscript to a SpringerOpen ${ }^{\circ}$ journal and benefit from:}

- Convenient online submission

- Rigorous peer review

- Immediate publication on acceptance

- Open access: articles freely available online

- High visibility within the field

- Retaining the copyright to your article

Submit your next manuscript at $>$ springeropen.com 